\title{
Violência Obstétrica: uma negação aos Direitos Humanos e a saúde sexual e reprodutiva da mulher
}

\author{
Obstetric violence: a denial of Human Rights and women's sexual \\ and reproductive health
}

\author{
Janaína Machado Sturza ${ }^{1}$ \\ Joice Graciele Nielsson ${ }^{2}$ \\ Estela Parussolo de Andrade 3
}

\begin{abstract}
RESUMO
A violência obstétrica representa uma grave violação ao direito à saúde das mulheres. Neste ideário, o presente artigo tem como objetivo analisar a violência perpetrada, sobretudo à mulher, na esfera do atendimento ao parto, trabalho de parto e pós-parto imediato, refletindo acerca das consequências destas práticas à saúde física e psíquica da parturiente. $\mathrm{O}$ artigo foi perspectivado a partir da hermenêutica fenomenológica, seguindo o método hipotético dedutivo, através de uma construção bibliográfica. Verificou-se que a violência obstétrica não é somente uma violação aos direitos humanos, mas sim (e essencialmente!) uma negação ao direito a saúde sexual e reprodutiva da mulher.
\end{abstract}

PALAVRAS-CHAVE:

Violência obstétrica, Dano, Vulnerabilidade, Parto, Saúde reprodutiva.

\begin{abstract}
Obstetric violence represents a serious violation of women's right to health. In this way, this article aims to analyze the violence perpetrated, especially to women, in the sphere of childbirth care, labor and immediate postpartum, reflecting on the consequences of these practices on the physical and mental health of the parturient. The article was viewed from the phenomenological hermeneutics, following the deductive hypothetical method, through a bibliographic construction. Obstetric violence has been found not only to be a violation of human rights, but (and essentially!) A denial of women's right to sexual and reproductive health.
\end{abstract}

KEYWORDS:

Obstetric violence, Damage, Vulnerability, Childbirth, Reproductive health.

\footnotetext{
${ }^{1}$ Pós Doutora em Direito pela UNISINOS. Doutora em Direito pela Escola Internacional de Doutorado em Direito e Economia Tullio Ascarelli, da Universidade de Roma Tre/Itália. Mestre em Direito pela Universidade de Santa Cruz do Sul - UNISC. Especialista em Demandas Sociais e Políticas Públicas/UNISC. Professora na Universidade Regional do Noroeste do Estado do Rio Grande do Sul - UNIJUÍ, lecionando na graduação em Direito e no Programa de Pós Graduação em Direitos Humanos - Mestrado e Doutorado. Integrante do Grupo de pesquisa Biopolítica e Direitos Humanos (certificado pelo CNPq). Pesquisadora Gaúcha FAPERGS - PqG.

2 Professora-pesquisadora do Programa de Pós-Graduação Mestradoe Doutoradoem Direitos Humanos e do Curso de Graduação em Direito; Coordenadora da Especialização em Justiça Restaurativa e Mediação na UNIJUI. Doutora em Direito (UNISINOS), Mestre em Desenvolvimento (UNIJUI). Integrante do Grupo de Pesquisa Biopolítica e Direitos Humanos (CNPq).

${ }^{3}$ Mestranda e Bolsista UNIJUÍ do Programa de Pós-Graduação Stricto Sensu em Direito - Curso de Mestrado em Direitos Humanos da Universidade Regional do Noroeste do Estado do Rio Grande do Sul - UNIJUÍ, vinculada à linha de pesquisa Fundamentos e Concretização dos Direitos Humanos. Integrante dos Grupos de Pesquisa Fundamentação Crítica dos Direitos Humanos e Biopolítica e Direitos Humanos. Bacharela em Direito pela UNICRUZ - Universidade de Cruz Alta. Advogada. Especialista em Direito de Família e Sucessões pela Faculdade Damásio.
} 


\section{INTRODUÇÃO}

O acontecimento gravidez é atrelado ao sentimento de alegria, de fecundidade, de esperança. $\mathrm{O}$ nascimento de uma criança, desde a antiguidade, remete a muitos significados. Mas não é somente no contexto familiar que uma gestação é celebrada, isso porque, a geração de um novo ser garante a continuidade da espécie, perpetuando as gerações.

Até mais ou menos metade do século passado, as parteiras eram responsáveis por trazer ao mundo a criança à nascer. Eram as parteiras que se dirigiam até a residência da parturiente e lá exerciam seu ofício. Geralmente mulheres da comunidade exerciam esse mister, com apoio da família na condução do trabalho de parto.

No entanto, com o surgimento dos cursos de medicina, a formação de profissionais, a criação de hospitais e de maternidades, aliado à busca de maior segurança à via mulher e da criança, o parto domiciliar cedeu espaço aos partos hospitalares e medicalizados.

Neste cenário, em busca da aludida segurança, práticas médicas foram sendo concretizadas, muitas vezes mutilando o corpo físico e o psicológico da mulher. Diversas condutas e técnicas empregadas foram sendo institucionalizadas e naturalizadas e, a falta de conhecimento e de estudos acerca da temática, fez com que certos atos, hoje denominados de violência obstétrica, fossem e ainda sejam rotineiramente praticados.

Podemos exemplificar, como práticas características da violência obstétrica, cometidas contra a mulher grávida e sua família, inclusive, violências verbais, físicas, psicológicas, utilização de medicamentos que aceleram o parto e causam dor, com o intuito de diminuir o tempo do profissional no trabalho de parto, dentre tantos outros.

Importa referir, ademais, que essa espécie de violência não é somente perpetrada em face da parturiente, em que pese seja ela a principal vítima, mas também à família, como, por exemplo, nos casos em que é negado acesso do acompanhante durante o trabalho de parto, direito esse assegurado em lei federal. 
Não bastasse, a violência obstétrica não se dá apenas durante o trabalho de parto, ao contrário, ela vai desde o pré-natal, parto até o pós-parto, bem como nos casos de abortamento, inclusive. Tais situações de violência expõem a mulher a maior vulnerabilidade, oportunidade que seus direitos sexuais e reprodutivos são colocados à mercê dos agentes de saúde.

A violência durante o período gestacional é uma triste realidade enfrentada pelas mulheres, não só mulheres brasileiras, mas do mundo todo. Desta forma, a presente pesquisa explorará as diversas facetas e modos em que se dá a violência obstétrica e as ações e omissões que a caracterizam.

Na sequência, mostrar-se-á a preocupação da Organização Mundial da Saúde (OMS) em proteger e salvaguardar a saúde sexual e reprodutiva da mulher, com a elaboração de diversos documentos que preveem medidas de proteção e resguardo de seus direitos, trazendo ainda a baila a perspectiva a partir dos direitos humanos.

Por fim, será exposta a polêmica ocorrida neste ano de 2019 acerca da abolição do termo "violência obstétrica" das normas e políticas públicas pelo Ministério da Saúde e as conclusões retiradas do assunto proposto.

\section{CONTEXTO EM TORNO DA VIOLÊNCIA OBSTÉTRICA}

O descobrimento de uma gravidez é momento de alegria na vida de uma mulher e de toda a família, ao mesmo tempo em que também a sociedade é envolvida, já que esta gestação trará ao mundo uma nova vida, garantindo a continuidade da espécie humana. No entanto, em meio a este misto de alegria, expectativas, descobertas, sonhos e desejos, medos e dúvidas permeiam a maternidade.

O evento nascimento sofreu mudanças no decorrer do tempo. Até metade do século passado, o parto era domiciliar, através do auxílio de parteiras da comunidade e da ajuda de familiares. Com a chegada da medicina e a preocupação com a saúde da mulher e da criança, o parto passou a ser hospitalar. No entanto, o que deveria ser uma segurança e garantia à saúde 
da mulher, passou a atormentá-la, pois, a partir de então, é que casos de violência obstétrica começaram a acontecer (BITENCOURT E OLIVEIRA, 2019). Esse novo cenário é exposto por Oliveira e Albuquerque (2018, p. 38):

Os hospitais se tornaram palanque da obstetrícia moderna, em que a tecnologia é aplicada não só para salvar a vida das parturientes que dela necessitam, mas para otimizar o tempo do trabalho de parto e, em tese, minimizar potenciais riscos à integridade física da paciente. O parto hospitalizado responde a uma lógica industrial de produção, em que há uma série de prazos a serem cumpridos pelos profissionais, dentro de um período delimitado de tempo. Desta forma, se a mulher não concluir o trabalho de parto no tempo previsto, serão realizadas intervenções desnecessárias para que ela dê à luz no prazo determinado.

Em que pese os atos de violência obstétrica possam ocorrer em qualquer período da gravidez, é no parto que as mulheres se encontram em especial situação de vulnerabilidade, momento em que o sentimento de alegria cede espaço a um cenário perturbador, onde as mulheres experimentam um momento de abusos, desrespeito, maus-tratos e agressões, físicas e verbais.

Sobre esse estado de vulnerabilidade e fragilidade da mulher gestante, Oliveira e Albuquerque (2018, p. 38) manifestam-se:

[...] diariamente, milhares de gestantes e seus filhos sofrem com maus tratos praticados por profissionais da área da saúde, seja qual for a função que estes desempenham. Tal situação pode ocorrer, desde o primeiro momento em que a gestante descobre a gravidez e se prolongar até o pós-parto,justamente no período em que a gestante necessita de apoio, pois, encontra-se vulnerável.

E complementam a análise a partir do viés dos direitos humanos (2018, p. 41):

Do ponto de vista dos direitos humanos dos pacientes, a violência obstétrica infringe diversos direitos humanos, como: o direito à vida, direito de não ser submetido à tortura e tratamento cruel ou degradante, direito ao respeito pela vida privada, direito à informação, direito a não ser discriminado e direito à saúde, que serão discutidos mais adiante. Assim, deve-se considerar a violência obstétrica como prática que detém elevada propensão à violação dos direitos humanos da mulher.

Esta trise realidade, em total desacordo com os cuidados necessários à saúde sexual e reprodutiva da mulher, vai de encontro ao que preceitua a Organização Mundial de Saúde OMS, no documento denominado "Prevenção e Eliminação de Abusos, Desrespeito e Maustratos durante o Parto em Instituições de Saúde”, que prevê (2014, p. 1):

Assegurar o acesso universal aos cuidados em saúde sexual e reprodutiva de forma segura, aceitável e de boa qualidade, especialmente o acesso aos métodos contraceptivos e aos cuidados em saúde materna, pode reduzir drasticamente as taxas globais de morbidade e mortalidade materna. Nas últimas décadas, as taxas de 
assistência institucional para o parto melhoraram porque as mulheres estão sendocada vez mais incentivadas a utilizar as instituições de saúde para o parto, por meio de ações para geração de demanda, mobilização comunitária, educação, incentivos financeiros ou medidas políticas.

Este cenário de transição, do parto domiciliar para o parto médico-hospitalar, foi fator responsável, em grande medida, pelo significativo aumento do número de partos cesáreas. Enquanto a OMS recomenda em até $15 \%$ partos por cesariana, verificou-se que no Brasil esse percentual chega a 57\%, segundo alerta emitido pelo Fundo das Nações Unidas para a Infância - UNICEF (UNICEF, 2017).

O Ministério da Saúde, na Portaria n ${ }^{\circ} 353$, de 14 de fevereiro de 2017, que aprovou as Diretrizes Nacionais de Assistência ao Parto Normal, introduziu referido documento com o seguinte alerta (Ministério da Saúde, 2017, p. 4):

O nascimento no ambiente hospitalar se caracteriza pela adoção de várias tecnologias
e procedimentos com o objetivo de torná-lo mais seguro para a mulher e seu bebê. Se
por um lado, o avanço da obstetrícia contribuiu com a melhoria dos indicadores de
morbidade e mortalidade materna e perinatais, por outro permitiu a concretização de
um modelo que considera a gravidez, o parto e o nascimento como doenças e não
como expressões de saúde, expondo as mulheres e recém-nascidos a altas taxas de
intervenções, que deveriam ser utilizadas de forma parcimoniosa e apenas em
situações de necessidade, e não como rotineiras. Esse excesso de intervenções deixou
de considerar os aspectos emocionais, humanos e culturais envolvidos no processo,
esquecendo que a assistência ao nascimento se reveste de um caráter particular que
vai além do processo de parir e nascer. Quando as mulheres procuram ajuda, além da
preocupação sobre a sua saúde e a do seu bebê, estão também em busca de uma
compreensão mais ampla e abrangente da sua situação, pois para elas e suas famílias
o momento da gravidez e do parto, emparticular, é único na vidae carregado de fortes
emoções. A experiência vivida porelasneste momentopode deixar marcas indeléveis,
positivas ou negativas, para o resto das suas vidas.

O alto número de cesáreas não é empregado tão somente para salvaguardar a vida da gestante e da criança. Infelizmente, tal procedimento tem sido aplicado de forma indiscriminada, no intuito de otimizar o tempo de trabalho dos profissionais, e a própria cesárea pode ser considerada uma violência obstétrica, mecanizando o procedimento.

Neste cenário, muito bem alertam Gomes, Nielsson e Wermuth (2016, p. 95), segundo os quais "essa tendência revela uma preocupação não com a figura da mulher, mas sim com a ansiedade dos profissionais de saúde em reduzir o tempo do parto a todo custo".

O período de gravidez enfrentado pela mulher gestante vai muito além de um estado de transitoriedade. Ele engloba diversas mudanças físicas, biológicas e sentimentais. Embora possa parecer um momento de tranquilidade e de extrema felicidade, essa jornada muitas vezes 
não se desenvolve com todo o cuidado e respeito que se espera. Com propriedade Gomes, Nielsson e Wermuth (2016, p. 99) esclarecem:

O parto e o nascimento de um filho são eventos marcantes na vida de uma mulher.
Infelizmente muitas vezes são relembrados como uma experiência traumática na qual
a mulher se sentiu agredida, desrespeitada e violentadapor aqueles que deveriam estar
lhe prestando assistência. A dor do parto, no Brasil, muitas vezes, é relatada como a
dor da solidão, da humilhação e da agressão, com práticas institucionais e dos
profissionais de saúde que criam ou reforçam sentimentos de incapacidade,
inadequaçãoe impotência da mulhere de seu corpo.

No entanto, em um cenário de alta vulnerabilidade e fragilidade da mulher, desconhecimento de seus direitos, falta de informações, aliado a sua condição de pessoa do sexo feminino, infelizmente, são propensos à ocorrência de casos de violência obstétrica.

Não se tem ao certo um termo pré-definido e delimitado quanto ao conceito de violência obstétrica, podendo ser encontrado em diversas normativas de saúde, de conselhos de medicina e na literatura especializada. No entanto, alguns conceitos merecem aqui ser trasladados. Para Leite, Silva e Souza (2019, p. 159),

O termo Violência Obstétrica (VO) surgiu para evidenciar ações exercidas pelos
profissionais de saúde para com as mulheres, infringindo o direito da mesma e do seu
bebê, podendo ocorrer em qualquer fase do ciclo gra vídico-puerperal, deixando
muitas sequelas de caráter psicológico e/ou físico. A VO iniciou a partir do momento
em que o parto deixou de ser como antigamente, onde era caracterizado pelo seu
processo fisiológico, domiciliar e exclusivamente da mulher; perdendo a sua essência
e passando a ser no ambiente hospitalar, de forma mecânico e voltado para o médico,
a figura masculina.

O termo violência obstétrica foi criado para dar publicidade às agressões de que as mulheres são vítimas no decorrer da gestação, e não apenas no parto. Com maestria, a professora e enfermeira Freitas (2019, p. 01), assim conceitua o termo:

\begin{abstract}
A violência obstétrica se configura como uma negação dos direitos humanos e dos direitos sexuais reprodutivos às mulheres. Ela compreende qualquer ato que venha provocar dano físico, emocional, psicológico a essa mulher fazendo com que a experiência do parto e do nascimento sejam sentidas de modo negativo. Ela ocorre desde o pré-natal até o pós-parto e tem relação direta com os profissionais que estão assistindo.
\end{abstract}

Desta forma, percebe-se que a ocorrência da violência não se dá única e exclusivamente no momento do parto ou pelo médico obstetra. Trata-se, portanto, de violência que pode ser cometida desde o início da gestação até o pós-parto, podendo ser cometida por médicos, enfermeiros, etc. (FREITAS, 2019). 
Segundo Parto do Princípio (2012, p. 1), uma rede de mulheres usuárias do sistema de saúde, que luta pela promoção da autonomia das mulheres, a violência obstétrica é uma das formas de violência de gênero:

Caracteriza-se pela violência cometida contra a mulher grávida, e sua família em serviços de saúde durante a assistência ao pré-natal, parto, pós-parto, cesárea e abortamento. Pode ser verbal, física, psicológica ou mesmo sexual e se expressa de diversas maneiras explícitas ou veladas. Como outras formas de violência contra a mulher, a violência obstétrica é fortemente condicionada por preconceitos de gênero.

Muitas mulheres, e até mesmo seu grupo familiar, ignoram esse tipo de violência, por não conhecê-la, justamente quando ela se reproduz das mais variadas formas durante o estado gestacional da mulher, ocasionando a desumanização de sua pessoa, de modo que sua vida passa a não ser valorizada, pois é mais um número a ser registrado.

O preâmbulo da declaração da OMS quanto à Prevenção e Eliminação de Abusos, Desrespeito e Maus-tratos durante o Parto em Instituições de Saúde preconiza que (2014, p. 1) "Toda mulher tem direito ao melhor padrão atingível de saúde, o qual inclui o direito a um cuidado de saúde digno e respeitoso".

A gravidez compreende um período de mudanças dinâmicas, mais acentuadas e mais rápidas na vida de uma mulher, com severos e significativos impactos na sua saúde física e mental. Outrossim, atrelava-se às dores sentidas pelas gestantes durante o período de trabalho de parto como uma punição relacionada ao conceito religioso, por ter cometido o pecado original.

Durante esse período, o cuidado com a mãe é muito importante, mas muitas vezes é negligenciado. É preciso asseverar que se a gravidez não for conduzida com cuidado e respeito à mulher e ao seu corpo, neste momento delicado e de transição, diversas consequências negativas poderão advir, inclusive, por decorrência do estado puerperal, período este que ocorrem diversas e intensas modificações no estado das mulheres em um pequeno lapso de tempo.

A Convenção Interamericana para Prevenir, Punir e Erradicar a Violência contra a Mulher, também conhecida como Convenção de Belém do Pará, preceitua, no seu art. $1^{\circ}$, a violência contra a mulher como "qualquer ato ou conduta baseada no gênero, que cause morte, dano ou sofrimento físico, sexual ou psicológico à mulher, tanto na esfera pública como na 
esfera privada". O direito à saúde, previsto constitucionalmente (art. 196), garante que: “A saúde é direito de todos e dever do Estado, garantido mediante políticas sociais e econômicas que visem à redução do risco de doença e de outros agravos e ao acesso universal e igualitário às ações e serviços para sua promoção, proteção e recuperação”.

No Brasil, a discussão sobre o termo violência obstétrica, ainda que tímido, começou a ganhar destaque nos anos da década de 2000, após as influências exercidas nos países da Venezuela e Argentina (DE ASSIS, 2018).

O termo violência obstétrica não é muito conhecido, e tampouco exposto com regularidade, o que não significa que essa ausência decorra do fato de que não existam casos de violência. Ao contrário, trata-se de violência recorrente, mas que muitas vezes nem a mulher nem a família sabem que estão sendo vítimas.

\section{DAS DIVERSAS CONFIGURAÇÕES DE VIOLÊNCIA OBSTÉTRICA}

Diversas são as ações, e omissões que podem ensejar e configurar uma situação de violência obstétrica. $\mathrm{O}$ desconhecimento por parte da vítima e das pessoas ao seu redor de tal situação, fez com que a Defensoria Pública do Estado de São Paulo, em 2013, publicasse uma cartilha intitulada "Violência obstétrica: você sabe o que é?".

Trata-se de cartilha que exemplifica os tipos mais recorrentes de violência obstétrica que as mulheres podem vir a ser vitimadas, dividindo em três momentos: violência obstétrica na gestação, violência obstétrica no parto e violência obstétrica no atendimento em situações de aborto, e faz um alerta importante às autoridades públicas:

\footnotetext{
Em países como a Argentina e Venezuela, a violência obstétrica é reconhecida como um crime cometido contra as mulheres, e como tal deve ser prevenido, punido e erradicado. Para que a realidade da violência obstétrica mude, é necessário compreendê-la e denunciá-la, bem como assegurar que os casos em que ela aconteceu sejam acolhidos, apurados e julgados. É também necessário que se cumpram as leis e normas vigentes no país, que garantem às mulheres o peno exercício de sua cidadania, liberdade sexual e reprodutiva e direito à saúde.
} 
A violação contra os direitos das mulheres tem sido constantemente objeto de pauta pela OMS, conforme pode-se verificar (2014, p. 01):

No mundo inteiro, muitas mulheres sofrem abusos, desrespeito e maus-tratos durante o parto nas instituições de saúde. Tal tratamento não apenas viola os direitos das mulheres ao cuidado respeitoso, mas também ameaça o direito à vida, à saúde, à integridade física e à não-discriminação. Esta declaração convoca maior ação, diálogo, pesquisa e mobilização sobre este importante tema de saúde pública e direitos humanos.

Muitas mulheres não sabem que são vítimas de violência obstétrica, e só tomam conhecimento tempo mais tarde. Trata-se de uma prática, infelizmente, mais comum que se imagina, que está enraizada, impregnada e tão naturalizada, que as mulheres e até mesmo as pessoas do ciclo familiar da gestante não percebem que estão sendo vítimas.

Alguns exemplos de violência obstétrica podem ser relatados, como o uso de expressões grotescas e pejorativas, do tipo 'na hora de fazer não chorou' que podem colocar a mulher em situação de desespero, a peregrinação por uma vaga na maternidade, o uso indiscrimado da ocitocina $^{4}$ e da episiotomia ${ }^{5}$, a realização de procedimentos sem orientação à mulher, a realização de toques sucessivos e por diversas pessoas, lavagem intestinal e deixar a mulher sob dieta zero são apenas alguns dos exemplos que caracterizam essa violência (FREITAS, 2019).

Violências física, verbal e emocional, ridicularização, negligência, críticas quanto ao aspecto corporal, violação ao seu direito de escolha, cesáreas desnecessárias, não autorização de um acompanhante $\mathrm{e}$ ameaças são perpetradas no atendimento à mulher, tanto na rede pública como na particular hospitalar.

Um exemplo claro de violência obstétrica que é rotineiramente praticado, mas que não é conhecido como violência pela maioria do público, é o caso de cesáreas desnecessárias, que podem, inclusive, causar sérios danos à saúde da mãe e do feto, conforme advertem Gomes, Nielsson e Wermuth (2016, p. 95):

O fato é que a cirurgia cesariana apresenta um risco maior, tanto para a mulher quanto para o bebê, razão pela qual somente deveria ser praticada quando houvesse uma

\footnotetext{
4 Ocitocina é um hormônio produzido, vulgo "sorinho" utilizado sob o argumento de que este ajudará a mulher no momento do parto, acelerando o parto, é uma indução ao parto. No entanto, muitas vezes ele aumenta a dor e a contração uterina, e as mesma não recebem nenhuma analgesia ou outro método para aliviar a dor, colocando a mulher em risco de hemorragia além de diminuir a oxigenação do bebê.

${ }^{5}$ Epsiotomia é o corte na vagina para ampliar o canal do parto, aumentando o canal de passagem do bebê, no entanto por vezes é usado de forma indiscriminada, aumentando o risco de lesões sem necessidade.
} 
indicação médica formal, ou seja, quando presente um risco para a mãe, para o feto, ou para ambos. Dentre os riscos para a mulher, salienta-se: lacerações acidentais, hemorragias, infecções, embolia pulmonar, íleo paralítico e reações indesejáveis à anestesia, complicações em gestações futuras, limitação do futuro obstétrico da mulher. Em relação à criança, destacam-se os riscos de maior frequência de desconforto respiratório, síndrome da angústia respiratória e prematuridade iatrogênica.

É importante falar sobre o assunto, pois deixar cair no esquecimento significa um total descaso com o corpo da mulher, o menosprezo a sua condição enquanto ser sujeito de direitos, além de expô-la a uma condição de negação de sua saúde sexual e reprodutiva.

Podem praticar referida violência médicos(as) obstetra, enfermeiros(as), anestesistas, técnicos(as) de enfermagem, recepcionistas, administradores(as) de hospitais etc., ou seja, todos aqueles que estão de algum modo envolvidos no desenvolvimento gestacional da parturiente.

Nesse contexto, verifica-se que a suspensão ou restrição do direito destas mulheres sugerem a transformação de suas vidas em vidas nuas, ou seja, uma vida vulnerável e que pode ser facilmente controlável e manejada (GOMES, NIELSSON E WERMUTH, 2016).

Verifica-se, portanto, que o corpo e a sexualidade da mulher é coisificada, deixando de ser protagonista dos cuidados que o contexto exige. Segundo Gualda (2002, p. 43)

Quando a mulherchega ao hospital, o primeiro procedimento é o da admissão. Marido
e familiares são separados da parturiente e esta é submetida à preparação para o parto.
Esta consiste de registro de informações úteis de ponto de vista clínico e obstétrico,
das condições físicas da mulher e do feto. Neste momento, são prescritos
procedimentos que incluem tricotomia, enteroclisma, banho, utilização de roupa
privativa do hospital, repouso jejum. A mulher não pode caminhar livremente ou,
mesmo, acomodar- se à vontade na cama. Seu corpo torna-se propriedade e
responsabilidade da equipe quea assiste e dita o comportamentoadequado. Da mulher
espera-se a passividade na convivência com as intervenções.

Da mesma forma, Gomes, Nielsson e Wermuth (2016, p. 94) apontam que: “medicalização excessiva e as intervenções desnecessárias apenas contribuem para aumentar a carga traumática do parto, o que pode acarretar danos à saúde física e psicológica das mulheres e crianças".

Face a esse cenário, o Ministério da Saúde, no ano de 2017, publicou as Diretrizes Naturais de Assistência ao Parto Normal, que prevê, em seu item 6.2, item 12 (2017, p. 15):

Mulheres em trabalho de parto devem ser tratadas com respeito, ter acesso às informações baseadas em evidências e serem incluídas na tomada de decisões. Para isso, os profissionais que as atendem deverão estabelecer uma relação de confiança 
com as mesmas, perguntando-lhes sobre seus desejos e expectativas. Devem estar conscientes da importância de sua atitude, do tom de voz e das próprias palavras usadas, bem como a forma como os cuidados são prestados.

Igualmente, outra forma de violência obstétrica cometida reiteradamente, é a não autorização de um acompanhante, indicado pela parturiente, durante todo o período de trabalho de pré-parto, parto e pós-parto imediato, direito esse assegurado pela Lei Federal $\mathrm{n}^{\mathbf{0}} 11.108$ de 2005.

É possível perceber que a violência obstétrica não ocorre tão somente no momento de trabalho de parto, mas sim desde o pré-parto até o pós-parto, e não atinge apenas a gestante, em que pese seja ela a mais prejudicada, mas também a sua família.

A fim de garantir a humanização no parto, no ano de 2010 foi criado, no âmbito do Ministério da Saúde, o Programa de Humanização no Pré-Natal e Nascimento, através da Portaria/GM n ${ }^{\circ} 569$, a partir da análise das necessidades específicas das gestantes, do recém nascido e no pós-parto, com o intuito macro de garantir a melhoria no atendimento. Referida portaria (2010, p. 5 e 6$)$ ainda prevê que:

\begin{abstract}
A humanização compreende pelo menos dois aspectos fundamentais. O primeiro diz respeito à conviç̧ão de que é dever das unidades de saúde receber com dignidade a mulher, seus familiares e o recém nascido. Isto requer atitude ética e solidária por parte dos profissionais de saúde e a organização da instituição de modo a criar um ambiente acolhedor e a instituir rotinas hospitalares que rompam com o tradicional isolamento imposto à mulher. O outro se refere à adoção de medidas e procedimentos sabidamente benéficos para o acompa nhamento do parto e do nascimento, evitando práticas intervencionistas desnecessárias, que embora tradicionalmente real izadas não beneficiam a mulher nem o recém nascido, e que com frequiência acarretam maiores riscos para ambos.
\end{abstract}

Ainda no ano de 2011, foi lançada, também pelo Ministério da Saúde, a Rede Cegonha, através da Portaria $\mathrm{n}^{\circ} 1.459$, visando $(2017, \mathrm{p} .1)$,

[...] proporcionar às mulheres saúde, qualidade de vida e bem estar durante a gestação, parto, pós-parto e o desenvolvimento da criança até os dois primeiros anos de vida. Tem o objetivo de reduzir a mortalidade materna e infantil e garantir os direitos sexuais e reprodutivos de mulheres, homens, jovens e adolescentes. A proposta qualifica os serviços ofertados pelo Sistema Único de Saúde (SUS) no planejamento familiar, na confirmação da gravidez, no pré-natal, no parto e no puerpério (28 dias após o parto).

Outrossim, como forma de diminuir os casos de violência obstétrica, e garantir um parto mais humanizado, tem-se oferecido às gestantes realizar o plano de parto, uma prática iniciada por mulheres europeias na década de 1970, mas que no Brasil ainda é um recurso subutilizado. 
Através dele, a mulher manifesta seus desejos e anseios para este período a partir de justificativas com evidências científicas.

Trata-se de um primeiro passo na busca de se evitar a prática da violência, a partir da manifestação de vontade e dos valores pessoais da mulher, garantindo seu direito à autoderminação e autonomia.

Como amplamente debatido, a violência obstétrica é uma prática recorrente, e muitas vezes não identificada por suas vítimas, além de não ser objeto direto e vertical de políticas públicas de atenção à saúde e tampouco de legislações que garantam e promovam a proteção dos direitos da gestante. O que há é tão somente um Projeto de Lei $n^{\circ} 7.633 / 2014$, que dispõe sobre a humanização da atenção à mulher e ao recém-nascido durante o ciclo gravídicopuerperal.

No contexto latino-ameriano, a Venezuela foi o primeiro país a prever a expressão "violência obstétrica" em lei, no ano de 2007, como fruto de reivindicação do movimento feminista local, e também por ser um problema social, político e público (SENA E TESSER, 2017).

Não bastasse essa ausência de proteção legislativa e jurídica, e o parco interesse das autoridades em expor o assunto e prevenir que tais condutas sejam cometidas, nos últimos meses o tema da violência obstétrica ganhou ênfase e relevância no cenário público e político, após ter sido objeto de análise pelo Ministério da Saúde, através do desejo da supressão do termo de documentos públicos e oficiais.

Isso porque, em atendimento à solicitação de manifestação do Ministério da Saúde, quanto ao uso do termo violência obstétrica, referido órgão proferiu despacho na data de 09 de maio de 2019, que, em suma, mencionou que "a expressão "violência obstétrica" não agrega valor e, portanto, estratégias têm sido fortalecidas para a abolição do seu uso com foco na ética e na produção de cuidados em saúde qualificada", concluindo pela "impropriedade da expressão "violência obstétrica" no atendimento à mulher, pois acredita-se que, tanto o profissional de saúde quanto os de outras áreas, não tem a intencionalidade de prejudicar ou causar dano". Na mesma oportunidade, o Ministério da Saúde determinou a exclusão da nomenclatura dos documentos oficiais (MINISTÉRIO DA SAÚDE, 2019). 
Neste soada, o Ministério Público Federal, através de sua Procuradoria da República no Estado de São Paulo, em 07 de maio de 2019, considerando o inquérito civil $\mathrm{n}^{\circ}$ 1.34.001.007752/2013-81, instaurado a partir de denúncias apresentadas por vítimas de violência obstétrica, expediu uma recomendação, no sentido de que negar o termo ou proibir seu uso é negar a existência da violência sofrida por mulheres no Brasil e no mundo, concluindo que o posicionamento do Ministério da Saúde vai de encontro ao direito fundamental da mulher a um atendimento de qualidade obstétrico.

Em que pese a manifestação ministerial, além de tantas outras entidades, entendeu o Ministério Saúde, em nítido retrocesso social, reconhecer o direito de as mulheres usarem a expressão "violência obstétrica", porém manteve a decisão de não usar esse termo em suas normas e políticas públicas.

Vislumbra-se, portanto, um total descaso e despreocupação com referido instituto, que não dá a devida importância a uma questão séria e complexa de ordem pública e social. Ademais, o não uso do termo favorece o desconhecimento da população de seus direitos, e tornam os cidadãos manipuláveis e fantoches por parte daqueles que detêm que o poder superior.

A preocupação com a saúde da mulher gestante e a primazia de continuidade e segurança de sua vida fez com que, no ano de 1994, se estabelecesse o Dia Nacional pela Redução da Mortalidade Materna, celebrado em 28 de maio.

Essa negligência em regulamentar o assunto, e a medida do Ministério da Saúde legitima práticas de violência, garantindo sua institucionalização, fazendo com que, muito bem advirta Bitencourt e Oliveira (2019, p.1), "Essa violência pode ser muitas vezes invisível aos olhos de suas vítimas, sendo em geral naturalizado e aceito por todos”.

Para a advogada criminal Gorga (2019, p. 1), em entrevista concedida à Radio Brasil de Fato, essa medida do Ministério da Saúde:

É uma tentativa de alterar o discurso para deslegitimar as mulheres que sofrem a violência. Se buscafechar o discurso, tirando a palavra de circulação. Como se discutir violência se não se pode usar esse termo? Se tira a conotação dessa atitude por meio do controle do discurso, o que é muito grave. Ainda mais porque estamos com um governo que toma ações ideológicas constantemente. 
Segundo pesquisas realizadas no Brasil pela Fundação Perseu Abramo juntamente com o Sesc, no ano de 2010, ficou evidenciado que uma a cada quatro mulher brasileira já foi vítima de violência obstétrica.

A violência obstétrica além de violar os direitos das mulheres, viola o seu direito à saúde e os direitos sexuais e reprodutivos, além de ser um grave problema de saúde pública. $\mathrm{O}$ artigo 12, da Convenção sobre a Eliminação de Todas as formas de Discriminação contra a Mulher prevê que:

Os Estados-Partes garantirão à mulher assistência apropriada em relação à gravidez, ao parto e ao período posterior ao parto, proporcionando assistência gratuita quando assim for necessário, e lhe assegurarão uma nutrição adequada durante a gravidez e a lactância.

Nesse sentido se faz necessária a presença do Estado, a fim de regulamentar a proibição e o uso de tais medidas, que caracterizam violência obstétrica. Corroboram tal afirmativa Marrero e Bruggemann (2017, p. 1226), ao dispor:

Dada a característica multifatorial da violência institucional no parto, diferentes segmentos da sociedade (governos, sociedade civil, entidades representativas de classe de trabalhadores de saúde, institutos formadores e pesquisadores) devem discutir a construção de políticas e diretrizes eficazes no combate ao problema. Isso porque, uma das faces da violência institucional no parto, e a estrutural, que conclama o estado a atuar com mais vigor em sua prevenção, ampliando o acesso a serviços de atenção ao parto de qualidade, com infraestrutura adequada, recursos humanos e materiais suficientes; e o poder público na criação de dispositivos legais e sociais que permitam o exercício da igualdade e da dignidade da mulher.

A garantia de ter sua vida e sua saúde sexual e reprodutiva assegurada, fez com que a OMS assim se manifestasse:

Todas as mulheres têm direito ao mais alto padrão de saúde atingível, incluindo o direito a uma assistência digna e respeitosa durante toda a gravidez e o parto, assim como o direito de estar livre da violência e discriminação. Os abusos, os maus-tratos, a negligência e o desrespeito durante o parto equivalem a uma violação dos direitos humanos fundamentais das mulheres, como descrevem as normas e princípios de direitos humanos adotados internacionalmente.

Ademais, necessária, imperiosa e urgente se dá a implemtnação de politícas públicas acerca do tema, a fim de conseguir atingir o maior número de mulheres vítima da violência. Da mesma forma Sena e Tesser (2018, p. 216):

No entanto, para que políticas públicas efetivas possam ser propostas e mudanças possam ser realizadas, é preciso conhecer, de fato, a realidade da assistência ao parto e esmiuçar, ainda mais, o contexto da violência obstétrica no Brasil. Para isso, acessar as experiências das mulheres sobre o que elas mesmas viveram no nascimento de seus 
filhos torna-se uma ferramenta de fundamental importância no contexto da desmedicalização e humanização do parto e nascimento.

Para Szermeta e Penna (2019, p.1), referidas medidas garantirão a humanização da gestação, de modo que,

Humanizar a gestação, o parto e o pós parto, implica em ter um sistema de saúde público adequado para que as mulheres sintam-se seguras, acolhidas e respeitadas, com seus medos, inseguranças e suas dores, dores que nem sempre são relacionadas ao concreto do parto - da ação médica - e sim ao concreto da vida, do cotidiano que se transforma ao ser mãe.

Trata-se, por sua vez, de um direito umbilicalmente ligado à dignidade da pessoa humana. Neste sentido, e no contexto apresentadoé que Martini e Sturza relatam (2019, p. 68):

[...] quando a Constituição Federal elencou a dignidade da pessoa humana como um dos princípios fundamentais da República, consagrou a obrigatoriedade da proteção máxima à pessoa por meio de um sistema jurídico-positivo formado por direitos fundamentais e da personalidade humana, garantindo assim o respeito absoluto ao indivíduo, propiciando-lhe uma existência plenamente digna e protegida de qualquer espécie de ofensa, quer praticada pelo particular, como pelo Estado.

Nos últimos anos os movimentos sociais vêm reivindicando atenção ao processo parturitivo, a fim de garantir a dignidade da mulher, ganhando certa visibilidade diante da publicização nas mídias sociais das denúncias relatadas por mulheres.

O desconhecimento do assunto pelos mais interessados apontam a necessidade de discussão do tema. A invisibilidade desta violência corrobora para que outros tantos casos sejam praticados, além de dificultar o enfrentamento desta questão de saúde pública e o planejamento de ações.

As mulheres, em especial, no contexto desta pesquisa, vêm lutando por uma gestação segura, saudável e humanizada, sem resquícios de um parto institucionalizado, agressivo e violento, justamente por se tratar uma fase sensível da vida da mulher, a mercê de pressões psicológicas, familiares e sociais.

Sujeitá-la a mais um constrangimento desnecessário viola seus direitos sexuais e reprodutivos, fere sua imagem e autoestima e atenta diretamente contra sua dignidade, valores esses assegurados na carta constitucional e nas mais diversas normativas internacionais. Não tratar o tema como sendo um caso de saúde pública, merecedor de atenção é atrelar à condição da mulher gestante a um mero objeto ou coisa, sujeita ao livre arbítrio daqueles que serão 
responsáveis por sua integridade física, nesse longo e árduo percurso que é a gestação, razão pela qual sua vida deve ser tratada com dignidade e respeito.

\section{CONSIDERAÇÕES FINAIS}

Após a discussão e análise acerca da pesquisa realizada sobre o assunto, constatou-se o quão carente e vulnerável é o universo vivenciado pelas mulheres gestantes. Não bastasse a fragilidade do momento, ainda são vítimas de constantes e recorrentes agressões, justamente no momento em que mais precisam de apoio, compreensão e cuidados.

Verificou-se no decorrer da pesquisa que não há um consenso em relação ao conceito de violência obstétrica no Brasil, embora as evidências indiquem que essa prática ocorra no pré-natal, durante o trabalho de parto e no pós-parto imediato, pelos mais variados tipos de violência e profissionais encarregados do cuidado da gestante.

Ademais, é preocupante a ausência de legislação e de políticas públicas específicas à matéria. Ainda, a falta de informação faz com que um grande número de mulheres vítimas de violência obstétrica, bem como seus familiares, não saibam de que estão sendo agredidos, devido ao desconhecimento de seus direitos, já que estes não são estimulados pelo Poder Público e tampouco interessa aos profissionais de saúde revelá-los, o que facilita a manipulação destes sujeitos.

Por fim, conclui-se que o parto é um momento complexo, de forma que afeta os processos biológicos, físicos e emocionais da gestante, de modo que merece ser tratado com urbanidade e respeito a sua especial condição de pessoa humana, a fim de garantir que seu processo gestacional ocorra de maneira mais segura e harmônica possível, garantindo a liberdade e autonomia sobre seu corpo e sua sexualidade. 


\section{REFERÊNCIAS}

ALBUQUERQUE, Aline; OLIVEIRA, Luaralica Gomes Souto Maior de. Violência obstétrica e direitos humanos dos pacientes. In: Revista CEJ, Brasília, Ano XXII, n. 75, p. 36-50, maio/ago. 2018. Disponível em: https://repositorio.uniceub.br/jspui/handle/235/11826. Acesso em: 07 ago. 2019.

ASSIS, Francisca de. Interseccionalidade, racismo institucional e direitos humanos: compreensões à violência obstétrica. 2018. Disponível em: www.scielo.br/scielo.php?script=sci_arttext\&pid=S0101-66282018000300547\&lang=pt. Acesso em: 07 ago. 2019.

BITENCOURT, A. C.; OLIVERIA, S.L. Significado e percepção de violência obstétrica para os profissionais que atuam na assistência ao trabalho de parto e parto. In: SEMINÁRIO DE INICIAÇÃO CIENTÍFICA FAPEMIG, 1., 2019, Itajubá. Anais... Itajubá: FWB, 2019.

BRASIL. Constituição da República Federativa do Brasil de 1988. Presidência da República. Disponível em: http://www.planalto.gov.br/ccivil_03/constituicao/constituicao.htm. Acesso em: 07 ago. 2019.

BRASIL. Lei Federal no 11.108, 07 de abril de 2005. Presidência da República. Altera a Lei no 8.080, de 19 de setembro de 1990, para garantir às parturientes o direito à presença de acompanhante durante o trabalho de parto, parto e pós-parto imediato, no âmbito do Sistema Único de Saúde - SUS. Disponível em: http://www.planalto.gov.br/ccivil_03/_Ato20042006/2005/Lei/L11108.htm. Acesso em: 07 ago. 2019.

BRASIL. Portaria n ${ }^{\circ}$ 353, 14 de fevereiro de 2017. Ministério da Saúde. Aprova as Diretrizes Nacionais de Assistência ao Parto Normal. Disponível em: http://www.in.gov.br/materia//asset_publisher/Kujrw0TZC2Mb/content/id/20805342/do1-2017-02-20-portaria-n-353-de14-de-fevereiro-de-2017-20805260. Acesso em: 07 ago. 2019.

BRASIL. Portaria ${ }^{\circ}$ 569, 01 de junho de 2000. Ministério da Saúde. Institui o Programa de Humanização no Pré-natal e Nascimento, no âmbito do Sistema Único de Saúde. Disponível em: http://bvsms.saude.gov.br/bvs/saudelegis/gm/2011/prt1459_24_06_2011.html. Acesso em: 07 ago. 2019.

BRASIL. Portaria n ${ }^{\circ}$ 1.459, 24 de junho de 2011. Ministério da Saúde. Institui, no âmbito do Sistema Único de Saúde - SUS - a Rede Cegonha. Disponível em: http://www.in.gov.br/materia/-/asset_publisher/Kujrw0TZC2Mb/content/id/20805342/do1 2017-02-20-portaria-n-353-de-14-de-fevereiro-de-2017-20805260. Acesso em: 07 ago. 2019.

CONVENÇÃO INTERAMERICANA PARA PREVENIR, PUNIR E ERRADICAR A VIOLÊNCIA CONTRA A MULHER. Disponível em: http://www.cidh.org/Basicos/Portugues/m.Belem.do.Para.htm. Acesso em: 07 ago. 2019.

CONVENÇÃO SOBRE A ELIMINAÇÃO DE TODAS AS FORMAS DE DISCRIMINAÇÃO CONTRA A MULHER. Disponível em: http://www.planalto.gov.br/ccivil_03/decreto/2002/D4377.htm. Acesso em: 07 ago. 2019. 
DEFENSORIA PÚBLICA DO ESTADO DE SÃO PAULO. Violência obstétrica: você sabe o que é?. Disponível em: https://www.defensoria.sp.def.br/dpesp/repositorio/41/violencia\%20obstetrica.pdf. Acesso em: 07 ago. 2019.

FUNDO DAS NAÇÕES UNIDAS PARA A INFÂNCIA - UNICEF. UNICEF alerta para elevado número de cesarianas no Brasil. Disponível em: https://nacoesunidas.org/unicef-alertapara-elevado-numero-de-cesarianas-no-brasil/. Acesso em: 07 ago. 2019.

FREITAS, Waglânia. Plano de parto previne violência obstétrica. Disponível em: https://www.ufpb.br/ufpb/contents/noticias/201cplano-de-parto-previne-violenciaobstetrica201d-alerta-pesquisadora-da-ufpb. Acesso em: 07 ago. 2019.

FUNDAÇÃO PERSEU ABRAMO. Mulheres brasileiras e gênero nos espaços público e privado. Saúde reprodutiva e abortamento. São Paulo, 2010. Disponível em: http://www.campanhapontofinal.com.br/. Acesso em: 07 ago. 2019.

GOMES, P. R. F.; NIELSSON, J. G.; WERMUTH, M. A. D. Uma análise biopolítica do parto e da violência obstétrica no Brasil. In: Universitas JUS, v. 27, n. 2, p. 87-101, 2016. Disponível em: https://www.publicacoesacademicas.uniceub.br/jus/article/view/4273. Acesso em: 07 ago. 2019.

GORGA, Maria Luiza. Dor ignorada, vítimas de obstétrica relatam agressões durante o parto. São Paulo (SP), 10 de maio de 2019. Disponível em: https://www.brasildefato.com.br/2019/05/10/dor-ignorada-or-vitimas-de-violencia-obstetricarelatam-agressoes-durante-o-parto/. Acesso em: 07 ago. 2019. Entrevista.

GUALDA, D. M. R. Eu conheço minha natureza: a expressão cultural do parto. Curitiba: Maio, 2002.

LEITE, D. B.; SILVA, F. L.; SOUZA, A. L. Reflexões sobre as agressões causadas ao psicólogo materno pela violência obstétrica: um estudo de revisão integrativa. In:

Rev. UNINGÁ, Maringá, v. 56, n. S1, p. 159-171, 2019. Disponível em: http://revista.uninga.br/index.php/uninga/article/view/2060. Acesso em: 07 ago. 2019.

MARRERO, Lihsieh; BRUGGEMANN, Maria Odalea. Violência institucional durante o processo parturitivo no Brasil: revisão integrativa. Disponível em: http://www.scielo.br/scielo.php?script=sci_arttext\&pid=S0034-

$71672018000301152 \& \operatorname{lng}=\mathrm{en} \& \operatorname{lng}=\mathrm{en}$. Acesso em: 07 ago. 2019.

MARTINI, Sandra Regina; STURZA, Janaína Machado. Direitos Humanos: saúde e fraternidade. Porto Aelgre: Ecangraf, 2019.

MINISTÉRIO DA SAÚDE. Despacho do dia 03 de maio de 2019. Disponível em: https://sei.saude.gov.br/sei/controlador_externo.php?acao=documento_conferir\&codigo_verif icador=9087621\&codigo_crc=1A6F34C4\&hash_do\%E2\%80\% A6. Acesso em: 07 ago. 2019. 
MINISTÉRIO PÚBLICO FEDERAL. Recomendação no 29/2019. Disponível em: http://www.mpf.mp.br/sp/sala-de-imprensa/docs/recomendacao_ms_violencia_obstetrica.pdf/. Acesso em: 07 ago. 2019.

ORGANIZAÇÃO MUNDIAL DE SAÚDE. Prevenção e eliminação de abusos, desrespeito e maus-tratos durante o parto em instituições de saúde. Disponível em: https://apps.who.int/iris/bitstream/handle/10665/134588/WHO_RHR_14.23_por.pdf?ua=1 . Acesso em: 07 ago. 2019.

PARTO DO PRINCÍPIO - Mulheres em Rede pela Maternidade Ativa, Dossiê da Violência. Violência Obstétrica. Disponível em: https://www.partodoprincipio.com.br/o-que---viol-nciaobst-trica. Acesso em: 07 ago. 2019.

SENA, Ligia Moreiras; TESSER, Charles Dalcanale. Violência obstétrica no Brasil e o ciberativismo de mulheres mães: relato de duas experiências. Disponível em: http://www.scielo.br/scielo.php?pid=S1414-

32832017000100209\&script=sci_abstract\&tlng=pt. Acesso em: 07 ago. 2019.

SZERMETA, Natalia; PENNA Isa. Ministério da Saúde adverte: Violência Obstétrica não existe, tá ok? Disponível em: http://midianinja.org/natalia-szermeta/ministerio-da-saudeadverte-violencia-obstetrica-nao-existe-ta-k/. Acesso em: 07 ago. 2019.

Data de Submissão: 23/12/2019

Data de Aceite: 18/05/2020 